\title{
Law's artifactual nature: how legal institutions generate normativity
}

\author{
KENNETH EHRENBERG
}

There can be no doubt that law presents itself as a system of norms. The doubts arise when we start to ask how and to whom those norms apply, if ever. In recent decades much of the discussion in attempts to answer those doubts has focused on notions of validity. Sometimes the discussions of validity have centered on a kind of contextual, practice-centered sort of validity we know as legal validity. While some people have tried to show a direct relationship between that practice-centered validity and a wider sort of moral normativity, a consensus has formed (between legal positivists and modern natural lawyers) that legal validity itself need not be directly dependent upon that wider validity. Sometimes the discussions have been more directly about that wider validity - what makes it the case, if ever, that one has a good reason to obey (or at least conform one's behavior) to the law. Those discussions are about what might give law (at least some of ) the authority it claims for itself. If that authority is legitimate, then the law's norms (where legitimate) are valid in a broader way. That is, where it is legitimate, we have good reason to obey the law, where that reason applies to us as human beings or members of a given community and not merely as legal addressees.

The difficulties arise in the space between the two validities: how to get from a merely practice-dependent normativity to the wider normativity to which the law aspires.

Some have tried to deflate this problem altogether, arguing it is not really one for legal philosophers to concern themselves with, or that the way in which the law activates our wider norms is unproblematic since it cannot really create any new norms in that wider sphere. I want to explore the idea that it is for legal philosophers to investigate and that there is a possibility for the law's creation of new practice-centered norms to imply the 'robust' creation of new reasons applicable in the wider sphere. I contend this possibility is to be found not so much in an investigation of the validity conditions or the legitimization of legal 
authority by themselves, but in the relation between these facets and law's ontology. A better understanding of law's nature will answer questions about how its normativity arises and connects to us as human beings or community members, rather than only as legal addressees.

The basic idea is that law is an institution and that a deeper understanding of institutions will allow us to see how they can create new non-prudential reasons for those subject to the institution. The focus on non-prudential reasons is justified because they are clearly more difficult to create anew and also because we are used to seeing the law create prudential reasons when it threatens us with coercion. In this latter case, 'trigger' is more apt than 'create' precisely because our basic prudential reasons are mostly already present. ${ }^{1}$ It is merely by altering empirical and contingent facts that those prudential reasons are triggered. The focus on non-prudential reasons is also appropriate precisely because attempts to issue authoritative directives are attempts to create a duty, ${ }^{2}$ and duties are a usual form that non-prudential reasons take. ${ }^{3}$

The question of who is subject to an institution is ultimately a question of what legitimates its authority. But seeing precisely where the questions of its authority arise can allow us to understand how its claims to impose reasons might be valid more broadly. To say that law is an institution is to say that it is intentionally created by human beings to serve a purpose, which is to say that institutions are (generally) special kinds of artifacts, ${ }^{4}$

1 This is true in the sense that the paths we take to happiness or wellbeing can change throughout our lives, as our characters and abilities change, interests wax and wane, and new relationships are formed and lost. In distinguishing between the triggering and creation of reasons I am borrowing some ideas of David Enoch. See "Authority and Reason-Giving," Philosophy and Phenomenological Research (forthcoming: http://onlinelibrary.wiley.com/ doi/10.1111/j.1933-1592.2012.00610.x/abstract), and "Reason-Giving and the Law," in Leslie Green and Brian Leiter (eds.), Oxford Studies in Philosophy of Law, vol. I (Oxford University Press, 2011), although I do not follow his precise understanding of the nature of this distinction, as will become apparent.

2 "[T]he distinctive feature of authorities is that the reasons they can give robustly are reasons of a special kind, duties." Enoch, "Authority and Reason-Giving," 11, emphasis in original.

3 Aesthetic reasons (insofar as they are still reasons for action as opposed to belief) are arguably another form in which we see non-prudential reasons, but they need not concern us here.

4 Amie L. Thomasson, "Realism and Human Kinds," Philosophy and Phenomenological Research 67 (2003) 580-699, at 592. Hart claimed "that legal obligations are very often (though not always) human artifacts." H. L. A. Hart, "Legal and Moral Obligation," in Richard E. Flathman (ed.), Concepts in Social and Political Philosophy (New York: Macmillan, 1973), 188 (immediately extending this to include "rights, powers, immunities and disabilities"), the caveat likely reserved for customary laws: understanding artifacts to 
albeit often abstract ones. Artifacts themselves are special kinds of tools. Tools are things created or adapted to perform a function. Artifacts are special in that they are created in order to be a specifically recognizable kind of tool. ${ }^{5}$ Institutions are special in that their ability to perform their function is dependent upon some kind of collective recognition, and not merely on their structural features. ${ }^{6}$ Hence institutions are understood in terms of their functionality, generally involving the conferral of a status that implies deontic powers. A deeper exploration of the relation of the institutionality of law to its normativity will answer questions about what lends potentially wider robust validity to the norms it claims to impose.

\section{The challenge of reasons and normative theory}

When we talk about the way in which the law creates or manipulates our reasons, there are two different kinds of reasons we might be talking about. ${ }^{7}$ There are reasons of which an agent is psychologically aware and which form the agent's beliefs about her justifications for her action or inaction, sometimes called 'motivating reasons.' When an agent is weighing the pros and cons of an action and resolves the decisionmaking process in favor of a specific option, the considerations weighed by the agent in favor of the option chosen and against the options rejected can be said to be the motivating reasons.

require deliberate creation. See also Brian Leiter, "The Demarcation Problem in Jurisprudence: A New Case for Scepticism," Oxford Journal of Legal Studies 31 (2011), 663-77, at 666. John Gardner follows Hart in noting that law, as a generality, is a "genre" of artifacts, while individual laws and legal systems are the actual artifacts. John Gardner, "The Legality of Law," Ratio Juris 17 (2004), 168-81, at 171. Elsewhere the word "kind" is used instead of "genre" (as in "artifactual kind"). Amie L. Thomasson, "Artifacts in Metaphysics," in Anthonie Meijers (ed.), Philosophy of Technology and Engineering Sciences (Amsterdam: Elsevier, 2009).

5 On the relation between tools and artifacts, see Randall R. Dipert, Artifacts, Art Works, and Agency (Philadelphia, PA: Temple University Press, 1993), 27-30. Thomasson argues that artifacts do not have to be understood or identified in terms of their functions in order to provide for artworks, but that many kinds still are best understood in terms of the functions they are to perform. Amie L. Thomasson, "Public Artifacts, Intentions and Norms," in Maarten Franssen et al. (eds.), Artefact Kinds: Ontology and the Human-Made World (Heidelberg: Springer, 2013). In conversation, Thomasson agreed that institutions are a kind of artifact understood in terms of their functions.

6 Thomasson, "Realism and Human Kinds," 585, citing John R. Searle, The Construction of Social Reality (New York: Free Press, 1995), 124.

7 My discussion here parallels that of Enoch, "Reason-Giving and the Law," 15. See also Ulrike Heuer, "Reasons and Actions and Desires," Philosophical Studies 121 (2004), 43-63, making the same distinction between "justificatory" and "explanatory" reasons. 
The other kind of reason that we might be talking about is a normative reason, which serves as a justification for an action. Sometimes this is called an 'objective reason,' although that locution seems to carry more metaphysical baggage. ${ }^{8}$ One important facet, however, of such reasons is that the agent can have them without being aware of it. This is the kind of reason one has to step aside when there is an anvil about to fall on one's head, even though one may be unaware of the anvil. As one type of such reasons, one can be under an obligation without acknowledging or being aware of the obligation. If we believe in the existence of a critical morality in some form, then we are implying that the critical morality entails normative reasons. Even beyond morality, if there are goals that are valuable to everyone regardless of whether one has personally adopted that goal, then we would say that everyone has a normative reason to pursue that goal. An example here might be happiness, understood as the ultimate source of all prudential reasons.

Non-prudential reasons can be motivational or normative. If one's belief that one has a reason to make a sacrifice motivates one to do so, then that belief is serving as a motivating reason. Generally, however, our interest here in non-prudential reasons is in their normative flavor since the main question is the relation between the institution of law and its putative creation of non-prudential reasons.

It might initially be supposed that there is no problem with the law creating objective normative reasons in the sense that there is no doubt that the law exists in some form (yet to be explained) and hence there is some 'reality' to the reasons it creates. If a given law is valid by the standards of validity in place for the jurisdiction in question, then it is 'real' law and therefore provides a kind of objective reason, although it is then a separate question whether anyone should ever follow that law upon weighing all reasons in play. There is some merit to this way of seeing things, especially as it seems to reflect an understanding of institutional reality. But our question is whether and how a particularly legal reason might break through to be a newly created objective normative reason for anyone to whom the law is addressed. To say that it is an objective reason in the way that it is addressed is to imply that it has a

${ }^{8}$ If one does not wish to be an externalist about reasons, one could believe that all of one's practical reasons are dependent upon one's "subjective motivational set" but that one could be unaware of all of the implications of the elements of that set. Bernard Williams, "Internal and External Reasons," in T. R. Harrison (ed.), Rational Action (Cambridge University Press 1979), 18. 
moral character of trumping at least some other reasons held by those to whom it is addressed. That is, it may preempt at least some of those other reasons. This it may do by being a reason to exclude those other reasons. ${ }^{9}$

If the law can create or manipulate objective normative reasons at all, it must be only in virtue of its legitimate (i.e. justified) authority and hence limited to those cases in which it is legitimate. So it might initially appear that natural law has a point in its favor: the law is deficient if it is not legitimately manipulating objective reasons, which it can only do when it is legitimately authoritative. That requires the legal directives to be morally acceptable. Hence, the only way for the law to impose objective reasons would be if they are reflecting objective reasons we already have, since it is these preexisting objective reasons that determine what is morally acceptable.

This is where Joseph Raz comes in to explain how the law could be manipulating objective reasons even where the law itself is only what humans have made it and subject only to the validity conditions that they make for it. On his view, legal validity is a kind of limit on law's claim to authority in that the claim only covers what is legally valid. However, what legitimates law's claim to authority is independent of that legal validity. What generally determines whether the law's claim to authority is legitimate according to $\mathrm{Raz}$ is whether the law's directive helps the subject to conform better to the right balance of reasons that already apply to her than she could do on her own. ${ }^{10}$ (Hence it is piecemeal in that legal authority is only legitimate for certain laws, applied to certain people, at certain times.) So it is possible for there to be a putative legal directive that would reflect the right balance of reasons but for it not to be legally valid (e.g. a valuable piece of legislation that is unconstitutional),

9 Here I follow Joseph Raz, Practical Reason and Norms, 2nd edn (Princeton University Press 1990; first published London: Hutchinson, 1975), 39. I also follow Raz in believing that these reasons, where normative, operate to exclude counter-indicating reasons from being acted upon, rather than deliberated about. Joseph Raz, "Authority and Justification," Philosophy and Public Affairs 14 (1985), 3-29, at 7; J. Raz, The Morality of Freedom (Oxford: Clarendon Press, 1986), 39. The opposing view can be seen in H. L. A. Hart, Essays on Bentham (Oxford: Clarendon Press, 1982), 253; Scott J. Shapiro, "Authority," in Jules L. Coleman and Scott Shapiro (eds.), The Oxford Handbook of Jurisprudence and Philosophy of Law (Oxford Universty Press, 2002), 406-7.

10 Raz, Morality of Freedom, 55-6; J. Raz, "The Problem of Authority: Revisiting the Service Conception," Minnesota Law Review 90 (2006), 1018. The notion of the "right balance of reasons" reflects the idea that there is possibly a correct answer in many situations where we are weighing reasons in deciding how to act, which we would arrive at if we were giving all of the applicable normative reasons their appropriate weight. 
and of course for there to be a legally valid directive that does not reflect the right balance of reasons (for that person, under those circumstances). Legal validity therefore serves as the determinant for the practicedependent normativity operative within the context of law. But authoritative legitimacy is the determinant for whether those practice-dependent norms succeed in having a wider 'robust' normativity and whether the law can therefore impart non-prudential reasons. ${ }^{11}$

Another way to approach this distinction is to consider the difference between an engaged and detached perspective from which to approach any normative system. Raz's example is of the meat-eater saying, "You ought not to eat that; it has meat," to his vegetarian friend. ${ }^{12}$ The meateater speaks to the friend from inside the normative system that the friend has embraced without thereby implying that he embraces it himself. From the external perspective, such as we might take as legal theorists, we can discuss the ways in which the norms operate on those for whom they are supposedly applicable without thereby implying that we endorse those norms. ${ }^{13}$

The problem of legal normativity can therefore be understood initially to be particularly acute for someone with positivist inclinations. If law is merely a human creation, made by certain events and actions we engage in, then it appears that whether something is a law is merely a matter of fact about a state of affairs in a given jurisdiction. That is, statements of the form 'Legally, one ought to $\Phi$ ' are merely asserting the existence of a state of affairs and not necessarily making any claims about what one ought to do, since it is always a separate question whether one should do it for that reason. To get from this fact about the law to the conclusion that "Here, one ought to $\Phi$ " we need some argument to get us over the apparent fact/value gap.

David Enoch denies this is necessary or that this is a problem for positivists, claiming instead that law merely purports to activate preexisting reasons that we already have. ${ }^{14}$ This might often be the case, but it is hard to swallow this claim in its entirety as the law does appear to

11 Most of the law's directives take the form of non-prudential reasons. Where they are legally valid but not authoritatively legitimate, the most they do is trigger a prudential reason by threatening coercion for non-compliance.

12 Raz, Practical Reason and Norms (1975 edn), 175-6. See also Joseph Raz, The Authority of Law (Oxford: Clarendon Press, 1979), 156-7.

13 This is not to say that acceptance of the norms is necessary, since whether consent is necessary for legal norms to apply is a separate question for political philosophy.

14 Enoch, "Reason-Giving and the Law." 
create wholly new reasons sometimes. By denying that the law creates new reasons whole cloth (rather than merely activating preexisting reasons), Enoch solves the problem of understanding the source of law's normativity. But this comes at the cost of going against what certainly seems to happen when the law sets forth how to make a valid will, or gives direction to Hart's "puzzled man," ${ }^{15}$ who is looking to the law for guidance. Take the example of flag law, ${ }^{16}$ the set of rules for how to treat the United States flag, which does not have any punishments for noncompliance. We can see that one who merely wants to be law-abiding now has a set of reasons for behaving in a certain way toward the flag. Even someone who had the motivation to be respectful toward the flag needs the law to set forth some of the standards for that respectful treatment. If I were so motivated, I might be able to intuit that I should not burn the flag, or perhaps not let it touch the ground. But how am I supposed to know that "respecting the flag" includes folding it into a triangle with the stars and blue field showing, or that it should be on its right when displayed with other flags? Wherever the law is not capturing preexisting behavioral standards but creating those standards, it creates reasons (rather than merely activates them) for those who are motivated or have good normative reasons to comply. A way to better understand this is to examine Enoch's claims to the contrary.

After distinguishing the giving of normative reasons into three groups: epistemic reason-giving (reminding someone of a preexisting reason that had already been applied), triggering reason-giving (activating a reason that the person already had but was not yet applicable), and "robust" reason-giving (creating a reason that did not exist before), ${ }^{17}$ Enoch claims that a legal reason is rather like an imaginary friend, in that the most it can be on its own is a reason in the context of a practice. ${ }^{18}$ This is akin to the idea that the rules of a game are only reasons for those already committed to playing the game. This will not be of much use to a greater understanding of law since any practice can create such reasons inside its own context. If we join him in seeing a clear distinction between legal reasons and real (normative) reasons, we can understand the force of

${ }^{15}$ H. L. A. Hart, The Concept of Law, ed. Penelope A. Bulloch and Joseph Raz 2nd edn (Oxford: Clarendon Press, 1994; first published 1961), 40.

16 Flag Code, 4 United States Code, $\$ \$ 3-9$.

17 Enoch, "Reason-Giving and the Law," 4-6. As we will see, he evenutally says that robust reason-giving is really just a special case of triggering reasons. David Enoch, "Giving Practical Reasons," Philosophers' Imprint 11 (2011), 1-22, 9.

18 Enoch, "Reason-Giving and the Law," 18. 
Raz's point that legal reasons are claims to impose or reflect normative reasons. Sometimes those claims might be true and sometimes they are false.

Law, seen this way, is a practice-context that has contextually bound reasons for people who are committed to that context in some way. For those already in the game and committed to playing it, the legal rules can be real rules to the extent that their commitment is morally valid or binding. This is not to say that once you are subject to the law in one area you are committed to playing the legal game and therefore must see those contextual reasons as real. Rather, as with many other contexts, you may sometimes be bound and other times you may not be bound. The rules themselves might in some cases be reasons not to participate in the context, especially if they lead one away from what one has good 'real' reasons to do.

A context-dependent reason is a kind of putative reason. It becomes a real normative reason when one is in that context and becomes committed to it (which may or may not happen voluntarily). But, pace Enoch, contexts are not quite the same as the realm of the imagination. Some putative contextual reasons may succeed in being real reasons regardless of whether one endorses the context. We do not say moral reasons are like imaginary friends precisely because everyone has a real reason to be moral, regardless of whether she has accepted anything about the moral 'context.' Law is somewhat weird because, seen from outside, it looks more like a context such as a game, while at the same time it appears to be making the claim that it is more like morality in providing real nonprudential reasons. It is that weirdness that is and should be of interest to legal philosophers and calls for our understanding. Why should we take this general claim on the part of law seriously at all, and what about law seems to necessitate this claim?

Enoch argues that robust reason-giving is itself a special instance of triggering reasons. His argument is based on the idea that no one can give a robust reason unless the recipient already has a conditional reason to treat the issuance as a reason. ${ }^{19}$ If my telling you to do something can actually give you a reason to do it, this must be because you already have a reason to do that thing if and when I tell you to do it. Hence my telling you to do something merely activates the condition precedent of your preexisting conditional reason. The upshot of this is that even instances

19 Enoch, "Giving Practical Reasons," 9-10. 
of what Enoch thinks can be considered robust reason-giving are actually still merely triggering these conditional reasons. ${ }^{20}$

This view strikes me as problematic in that it appears to suggest that one is born with all the reasons one will ever have in life (at least in some conditional form). There is something trivially true but also unilluminating about the claim in that every reason is conditioned upon some conditional precedent being true. To say that all instances of robust reason-giving are merely instances of triggering because one could come up with some antecedent conditional statement that was already true is almost like saying that nothing new ever happens because we can always come up with some statement about the past that was already true and included some conditional causal antecedents about the event in question.

In correspondence, Enoch has clarified that he thinks one is born with all of the "ultimate, grounding reasons" that one has in life, and that this group includes all of one's conditional reasons, with new reasons arriving as a result of those conditions being triggered. This has a number of implications that strike me as strange. One is that the conditional reason "I have a reason to take extra care to ensure the wellbeing of $\mathrm{H}$, if I marry her" and "I have a reason to take extra care to ensure the wellbeing of $\mathrm{H}$ " (where $\mathrm{H}$ is my wife) are two different reasons. Another one is that I am born with the first (conditional) reason, although admittedly not the second. This seems to imply that I have a conditional reason to take extra care to ensure the wellbeing of everyone on the planet (or at least those I could possibly marry). ${ }^{21} \mathrm{~A}$ third strange implication is that the grounds for any unconditional reason are always therefore a vast number of conditional reasons that have the unconditional reason as a consequent. When I think of the ground for a reason, I think of a more ultimate value that serves as the justification for that reason. I do not see how a tacked-on condition precedent is really a ground for that reason, even if it captures a set of empirical facts that would make the reason valid for me. We need to make a distinction between a more general reason that serves as a ground for more particular ones, and a precondition that must be present for a reason to exist (or apply). It seems reasonable to suppose that I am born with a reason to take extra care to ensure the wellbeing of those with whom I form a close

${ }^{20}$ More on what distinguishes this subclass of robust reason-giving below.

21 I probably have a non-conditional reason to take some care to ensure the wellbeing of everyone on Earth, but only a reason to take extra care of a small subset of them. 
relationship. This is the ground for my 'conditional reason' to take extra care to ensure the wellbeing of $\mathrm{H}$, if I marry her. But once that condition is met, the reason is not distinct from my reason to take extra care to ensure the wellbeing of $\mathrm{H}$.

I believe what is multiplying reasons here is the assumption that every logically distinct true proposition that describes a reason refers to a distinct reason. But my reason to take extra care to ensure the wellbeing of any woman who becomes my wife and my reason to take extra care to ensure the wellbeing of the woman who does become my wife are the same reason. Of course, there are unique things about the particular woman who became my wife that gave me additional distinctive reasons that are particular to her. But under Enoch's taxonomy, I would have already had an additional conditional copy of those reasons before I ever met her. Consider the following. On Enoch's view the statement "I have a reason to take extra care of $\mathrm{H}$, if I marry her" was true upon my birth, although "I have a reason to take extra care of $\mathrm{H}$ " was not true upon my birth. That proves to him that these are two distinct reasons, and that triggering is a form of reason creation. I claim, however, that both propositions refer to the same reason, even though one proposition was true at my birth and the other was not. The first proposition was true at my birth but the reason it described was not yet created. This seems required by some form of metaphysical parsimony about reasons, if the strange implications I noted above did not suffice. Hence a 'conditional reason' with an untrue (or not yet true) condition precedent is not (yet) a reason. This should not be so surprising. Assuming I can legitimately give my military subordinate a reason to clean parts of the barracks by ordering her to do so, I have not yet changed her reasons for action by saying to her "You must clean the latrine if I order you to do so." But when I say "I order you to clean the latrine," I have given her a new reason for action, even if that is grounded on preexisting general reasons to follow my orders regarding cleaning parts of the barracks.

While much of what I have to say about the ontology of legal norms may work even if one agrees with Enoch's picture of triggering and conditional norms, I think it is important to note the reasonableness of a picture that allows for the potential for law to create norms entirely anew.

Independently of its relation to triggering reasons, Enoch gives a communicated-intention-based account of robust reason-giving. ${ }^{22}$ There

22 Enoch, "Authority and Reason-Giving," 12-15. 
are three parts to the account: I must intend to give you a reason to $\varphi$ and communicate that intention to you; I must intend that you recognize my intention; and I must intend your reason to $\varphi$ to depend on your recognition of my communicated intention to give you a reason to $\varphi$. The worry then arises whether anything other than "persons or personlike organs can play the role of an authority." 23 That is, the ability to give a robust non-prudential reason such as a moral duty depends on the communication of an intention to do so, which is needed in order to distinguish the possibility of successful creation of duties from merely triggering preexisting non-prudential reasons. But building in this communicated-intention requirement seems to mean that only other people (or bodies) can be authorities, not the law itself. ${ }^{24}$ One easy solution to this problem is to say simply that the authority is vested in the lawmaker, whatever person or body that might be, and that talk of the authority of law is merely metaphorical. However, this solution does not sit well when we think of the antiquity of some legal norms that are still apparently binding, especially when some of those legal norms are borrowed directly from jurisdictions we would not think meet our normative requirements for political legitimacy (as is the case with the remaining American legal norms whose legal validity is sourced in medieval English law). This is precisely where the metaphysical questions about law become important. A better understanding of law's ontology will solve the problem of how a communicated intention can exist and possibly be robustly reason-giving when there is no identifiable human being or body we would identify as having the authority to address us directly. Creators' intentions about the content of the law and their communication to us are bound up into the law by its artifactual nature; their applicability across the ages is explained by its institutionality.

\section{Institutions, artifacts, and the communication of intention}

As mentioned above, institutions can be understood as a subclass of artifacts, although institutions may be abstract in that they might not be identical to whatever concrete entities they may be associated with.

23 Ibid.

24 To be fair, Enoch is agnostic about whether the law can communicate the necessary intentions to robustly give reasons. "Reason-Giving and the Law," 30, says that if the law is capable of robustly giving reasons, it must be carrying the complex intentions of the legislature. 
Institutions like universities are not identical to any set of physical entities such as their students, faculty, administrators, buildings, or land. Laws and legal systems are certainly abstract institutions in that they are not identical with the people constituting the legal officials, the words written in books or scrolls of law, or the geographic area of their jurisdiction. Even if abstract institutions frequently confer status on physical objects, the object should not be confused for the institution that conferred the status. Money is an institution; a piece of currency is not, although we can say whether a given piece of paper is money is an institutional fact about the paper. Under John Searle's theory, an institutional fact is created by the collectively intended assignment of a status function by using a constitutive rule. ${ }^{25}$ That status function conveys deontic powers, which is to say that the bearer of the status can "provide desire-independent reasons for action," ${ }^{26}$ including non-prudential reasons. The key is the collective acceptance of some set of conditions, which, if fulfilled, brings the institution into existence. The immediate questions are what are the normative grounds for that collective acceptance, i.e. what is a good reason to accept those conditions; how wide must that collective acceptance be; and how the status function conveys deontic powers.

The constitutive rule sets the conditions for membership and hence applicability of the institution's norms. Some institutions are relatively static and do not require much alteration after their creation. In these, there may not be much room for roles or offices. But in other, more dynamic, institutions, there will generally be roles or offices, themselves creations of the institution and which carry deontic powers to alter the (institutionally context-bound) normative space of those subject to the institution. In a legal institution, those deontic powers are themselves legal creations and are to be characterized as such. (The law is a special kind of institution in that one of its key functions is the creation of other institutions; legal systems are therefore institution-generating institutions.) The deontic powers are held by officials, or possibly by individual laws and regulations themselves if they can operate without official

25 Searle, Construction of Social Reality, 23-8. The constitutive rule tends to take the form "X counts as $\mathrm{Y}$ in context C." Thomasson broadens this to account for abstract institutional entities, which are not applied to preexisting objects. Thomasson, "Realism and Human Kinds," 587-8. Searle has also broadened his view, in part for the same reasons. John R. Searle, Making the Social World (Oxford University Press, 2010), 19-20.

26 Searle, Making the Social World, 23. 
intervention. ${ }^{27}$ They have a system or practice-based normativity applicable to anyone subject to that system. Again, we can analyze that normativity in two ways. The first way is merely in terms of the system itself as a practice and seeing the normativity it imposes through the creation of its institutional deontic powers. In this way we can analyze legal normativity in an external but engaged fashion, speaking about legal reasons as applying to whomever the system claims it applies, treating those legal subjects as practice participants. (It is far from unusual for other social institutions and practices to make normative claims upon more people than those who belong to it or acknowledge the authority of the institution to do so. Organized religions are one example.) The other way to analyze that normativity is to ask what might give someone a robust reason for being bound by those system norms. This is to inquire into the conditions for legitimating the claims that the law makes that all its directives are morally binding on those to whom they are directed. If they are truly morally binding, then those who are subject to them have a good reason to see themselves as bound, whether or not they acknowledge that reason.

Whether the norms are viewed contextually or robustly, however, what is important here is that it is possible for institutions to be created anew, usually by a kind of declaration that is collectively accepted. ${ }^{28}$ The new status that is created consists partially in the deontic powers that are conferred by the acceptance of the constitutive rule that creates the new status. This self-referentiality is an important feature of how collective acceptance confers status and creates norms. For something to have the properties of a given institutional kind, it must be believed to be of that kind; the belief that it is of that kind makes it so. ${ }^{29}$ Hence, part of what it is to have an institutional status is the ability to create new reasons for those subject to the institution. If the institution persists, then the new reasons it creates for those subject to it may also persist. Since the status and the new reasons created by the deontic powers are so closely linked, we can say that part of what it is for the institution to persist is for the reasons it creates to continue to apply. Conversely, by the time none of its created reasons any longer apply to anyone, the institution has ceased to

${ }^{27}$ I am here imagining some kind of system that automatically generates and sends a violation notice to motorists tripping a camera when running a red light.

28 Thomasson, "Realism and Human Kinds," 589; Searle, Making the Social World, 85-6.

29 Thomasson, "Realism and Human Kinds," 585, citing Searle, Construction of Social Reality, 32. 
exist (although other associated artifacts might continue to exist). Hence we have the beginnings of an answer to the question of how reasons created by people long dead and not authoritative in the properties they had when alive can continue to be applicable to us today. Their reasons retain their context-dependent normativity just in case their institutionality is still retained; they retain any robust normativity to the extent they are (now) legitimately authoritative to their addressees. They can continue to address people long into the future so long as the institution itself persists and that persistence depends on continued collective acceptance.

As for the questions of how the institution generates norms and who is in the ambit of collective acceptance, Amie Thomasson has a compelling argument that because an institution is a self-conscious creation, the group who collectively accepts the institutional status cannot be ignorant of or in serious error as to its nature or contents. ${ }^{30}$ The collective acceptance of the relevant set of conditions that are declared sufficient for the creation of the institution make it the case that those conditions are sufficient to create the institution. ${ }^{31}$ And we cannot be massively wrong about the instantiation of those conditions since it is generally our perception of those conditions which we declare sufficient for creation of the institution. ${ }^{32}$ Since the content of the institutional status is (partially) the desire-independent reasons it purports to create, those parts of the collective acceptance of the institution cannot be massively wrong about the creation of its norms.

This does not tell us anything about the scope or nature of that collective acceptance which creates the institution. ${ }^{33}$ It simply states that,

30 Thomasson, "Realism and Human Kinds," 588-90.

31 We can be wrong about necessary conditions and other conditions that are not criterial of the institution. Ibid.

32 The dispute between inclusive and exclusive legal positivists can be understood to be over whether the conditions sufficient for the creation of a legal institution must be perceptions (or beliefs). Both would agree that we cannot be wrong about the conditions sufficient for the creation of a legal institution (i.e. that the legal validity conditions are as the community determines them to be); they disagree about whether we can be wrong about whether those conditions are instantiated (i.e. whether there can be an element of those validity conditions the instantiation of which is beyond our epistemic access). The more serious or massive the error that inclusive positivism allows, the less likely it is consistent with this understanding of the metaphysics of institutions.

33 Thomasson's theory of artifacts does not depend on collective intentionality (Thomasson, "Artifacts and Human Concepts," in Eric Margolis and Stephen Laurence (eds.), Creations of the Mind: Theories of Artifacts and their Representation (Oxford University Press, 2007), 52), although her theory of institutions as a subset does (Thomasson, "Public Artifacts, Intentions and Norms," 54). Nevertheless, this understanding of 
where there is an institution, there is some group whose collective acceptance confers that institutional status, thereby implying the power to give reasons and alter the normative space for those subject to it. But that protection from error does not extend to individuals or to groups outside the collective whose acceptance creates and sustains the institution. ${ }^{34}$ This opens up the possibility for empirical research or discovery and highlights the importance of social scientific investigation into the conditions creating the institutions we see ourselves and others believing in.

We also have an answer for Enoch: he got the picture partially right but did not allow that questions of what makes legal normativity morally legitimate may still be an apt subject for legal philosophers. The reason that it is an apt subject is precisely that the law is claiming moral legitimacy. Hence, it is certainly within our dossier to comment upon that claim and to investigate the circumstances in which it may be accurate. In doing so, we may be admitting that the law is usually merely activating reasons that already apply, even when it does have moral legitimacy. But by acknowledging its institutional nature, we are open to the possibility that it creates new norms that were not originally present and merely activated by the law. They are sometimes akin to imaginary norms as Enoch claims would be the case with any merely practice-based norms. But where the law's claim to moral legitimacy is accurate (if ever) and where that accuracy coincides with the creation of a new norm that did not already apply to the subject, there is a space for law to make a real normative difference that Enoch does not acknowledge.

One might object here that, insofar as we are seeing legitimacy along Razian lines, in order for just about any legal directive to be legitimately authoritative, it must be based upon preexisting, "dependent" reasons. These are reasons that already apply to the person who is subject to the directive. If that is the case, the objection might go, then Enoch must still be right since the law is merely activating these preexisting dependent reasons. The answer is that, for a directive to be legitimately authoritative

institutions appears compatible with a range of different theories of collective intentionality. See ibid., citing Searle, Construction of Social Reality; Michael E. Bratman, Faces of Intention: Selected Essays on Intention and Agency (Cambridge University Press 1999); Margaret Gilbert, Living Together: Rationality, Sociality, and Obligation (Lanham, MD: Rowman \& Littlefield, 1996).

34 Thomasson, "Realism and Human Kinds," 591. 
under Raz, it need not be based directly on these dependent reasons; it need only reflect those reasons. ${ }^{35}$ While there must ultimately be underlying dependent reasons that apply to the subject, it is not the case that the law's directive must be directly based on those underlying reasons in order to be legitimate. If it is not based on those underlying reasons but merely reflecting them, then it opens up more space to say that the law is doing more than simply activating existing reasons.

One way to see this is to remember the complexity of reasons and how they are created. In order to be legitimately authoritative, the law's directives must at least reflect those underlying dependent reasons (according to Raz). This means that legal directives must ultimately aid the subject to comply with the correct balance of those reasons that already apply to her: the dependent reasons. Hence, on this model, it is easy to see a view like Enoch's get off the ground: if the law is merely reflecting preexisting reasons when legitimate, then the most it can do is either to remind us of the applicability of that preexisting reason (an "epistemic" form of reason-giving in his taxonomy) or to activate those preexisting reasons, perhaps marshaling them to coordinate behavior or otherwise provide the kind of guidance we need in order to comply with the best balance of all those reasons (a "triggering" form of reason-giving in his taxonomy). Since the law is merely changing social facts, the most it can do is trigger a preexisting normative reason one already had but was not yet applicable. ${ }^{36}$ For Enoch, to trigger a reason, a fact need only be "normatively significant," 37 but to provide a robust reason is for the communication itself to make the normative difference. That is, a robust instance of reason-giving requires, on Enoch's view, the reason's creation merely from facts about the communication, e.g. the intention to create such a reason in the listener and that the communication itself serve as the listener's reason. ${ }^{38}$ The idea is to capture the distinction between seeing a request as a reason to comply on its own, and seeing making the requester happy as an instrumental reason given further goals or values of the listener.

Most of the time when we accede to the law's demands of us, we are very likely seeing any reason-giving on the part of the law as triggering in Enoch's sense. But the law does purport to give us reasons merely because it is the law and not by triggering reasons that we already have. Is there a way to say that when it commands compliance merely because it is the law it is robustly reason-giving even if that command is only legitimate where it

\footnotetext{
35 Raz, Morality of Freedom, 51. $\quad 36$ Enoch, "Reason-Giving and the Law," 26.

37 Ibid. 38 Ibid.
} 
reflects preexisting reasons we already have? This depends again on whether one is sufficiently internal to the practice to see the law's reason-giving as robust, which itself depends on whether the directive is legitimate.

Here is where it becomes important to see laws as a genre of artifacts. They are artifacts in that they are specialized creations of human intentionality that serve specific purposes and are designed in order to be recognized as such. Artifacts themselves are a special case of tools, which would be anything adapted or used for a human purpose. Artifacts are distinct in that they are designed to be recognizable as the specific kind of tool that they are. That means at the very least that the creator of the artifact has in mind that others will see the artifact for the kind of thing it is supposed to do (where, as with law, we are dealing with public artifacts that are understood in terms of the function they are to perform). This is a kind of communication between creator and those who will in the future come into contact with the artifact. Hence, if Enoch is right that communicated requests can be sufficient for robust reason-giving, then it seems that artifact creators can perform a similar kind of communication merely through the creation of objects that are intended to be seen by others in a certain way. This does not mean that they are creating a reason to treat the object in a very precise way such that we are normatively bound not to repurpose those objects. But it does seem likely, as Amie Thomasson notes, that the identity of an artifact as a certain kind of thing does provide some robust norms of treatment. ${ }^{39}$

Imagine I sew the flag of a country in which we happen to be located. (Assume for the sake of simplicity that this country has no laws about how to treat its flag.) There are likely all sorts of norms that are thereby created with regard to this object I have made. They may not be precisely the norms I intended to create. For example, I may hate the government of that country and have created the flag with the intention that you burn it. Nonetheless, I still intend that the object be recognized as the flag and not, for example, as a dinner napkin. That seems to create a reason for you to treat it as a flag, even if one intended treatment in this case is to burn it. Now in making the flag-token I am also calling up its

39 Thomasson, "Public Artifacts, Intentions and Norms," 51. While Thomasson's aim in this article is to show that artifacts need not have intended functions in order to generalize the theory of the metaphysics of artifacts to include works of art, she acknowledges that some kinds of artifacts are to be understood in terms of intended functions. Ibid. She also agreed in conversation that individual laws have intended functions on her analysis and that law, as a genre of artifact (particularly an institutional one), is therefore to be understood in terms of those functions. 
institutional status. Hence, even if I wish you to burn the flag I created, if many norms of the wider institution are legitimate, that could undermine the reason-giving efficacy of my specific intention for you to burn it. (Even if there are no laws against flag burning, saying the norms of the institution are generally legitimate is to say that it is providing a valuable service in the creation of those norms. As a result there may be moral reasons not to burn its flag even if there are no legal reasons not to do so.) Hence, when I create the flag-token, some of my communicated intentions may be successfully norm-creating and others may not.

On Thomasson's analysis, something is an exemplar of an ("essentially" ${ }^{40}$ ) artifactual kind

only if it is the product of a largely successfully executed intention to make [an exemplar of that kind,] where the maker must have a substantive concept of the nature of [those artifacts] that largely matches that of some prior [ ] makers (if any) and intend to realize that concept by making an object with [ ] relevant features [of the kind]. ${ }^{41}$

We can broaden this to include institutional entities that are the result of collective creation and recognition. The key for our purposes is to recognize that some of those relevant features are "receptive." That is, they are "intended ways in which the object is to be regarded, used, or treated." $" 2$ This is not to say that the creator of the artifact must create it with the intention that it actually be recognized as a member of that kind. Rather, it is only necessary that (for public artifacts, which are our primary focus) it is intended to be "recognizable" at least to an intended audience. ${ }^{43}$ For many genres of public artifacts, the main (sometimes the only) thing that distinguishes them is the norms of treatment they receive and hence the recognizability of the artifact carries with it those norms of treatment. ${ }^{44}$ That is, for many such artifacts, what it is to be that artifact

40 "[A]n essentially artifactual kind is a kind that necessarily has in its extension all and only artifacts - considered as intended products of human action.” Ibid.

41 Ibid., citing "Realism and Human Kinds," 599-600.

42 Thomasson, "Public Artifacts, Intentions and Norms," 49.

43 Ibid. The limitation to "public artifacts" excludes artifacts that are designed not to be recognizable to anyone, or only to the creator. Institutions, requiring collective acceptance as they do, come within the class of public artifacts.

44 Ibid., citing Roman Ingarden, Ontology of the Work of Art, trans. Raymond Meyer (Athens: Ohio University Press, 1989; originally Untersuchungen zur Ontologie der Kunst, 1962), 260-1. Thomasson notes that these are genuine norms and not regularities of behavior as "misuse" of the artifact or "improper" behavior with regard to it are subject to "correction or rebuke." Thomasson, "Public Artifacts, Intentions and Norms," 53. 
is to bear those norms of treatment, and it is the intention of its creator that it carry those norms, which are thereby at least partially constitutive of its identity. ${ }^{45}$

Now we are closer to seeing how it must be possible to create completely new reasons for action upon creating artifacts and hence laws as a species of artifact. Since it is possible to create new artifact types, ${ }^{46}$ as well as to create new exemplars of existing artifact types that still differ from their predecessors in some of their structural or receptive features, ${ }^{47}$ it must be possible to create new norms of treatment that are constitutive of these new entities. To the extent that the artifact is a public kind, then those norms are addressed to the community that comprises the potential users of the artifact. This is not to say that the creator of a wholly new artifact type is necessarily successful in the particular norms of treatment that she might intend for her artifact. But for her creation to be successful at all, it generally will have to be recognizable as a member of a more general kind that comes with some norms already in place. When people recognize its value as a distinct type they will then start to generate additional norms of treatment that may or may not be in line with her intentions. The key for us to take away from this discussion of artifacts is the possibility of new norms, not from where they come or to whom they might apply. But when we think of institutions as a subclass of these public artifacts then we start to see a clearer picture of how people in certain roles might have privileged places from which to ensure those new norms are what they intend them to be and apply to that group within the institution's ambit.

\section{Conclusion}

Law as a genre is a type of institutionalized abstract artifact. That it is a type of artifact means that it has some receptive features, some of which are norms of treatment that its tokens tend to share. The creators of those tokens (legislation, judicial decisions, administrative rules, etc.) intend

45 Thomasson, "Public Artifacts, Intentions and Norms," 56. $\quad{ }^{46}$ Ibid.

47 Beth Preston calls this phenomenon of artifacts "reproduction with variation" and it is one of several phenomena characteristic of artifact functions that must be accommodated by any complete theory of artifacts. Preston, "Philosophical Theories of Artifact Function," in Meijers, Philosophy of Technology and Engineering Sciences, 216-17. As she and Thomasson both note, even new artifact types tend to be improvements upon existing broader artifact types in some way. Thomasson, "Public Artifacts, Intentions and Norms," 56. 
what they create to be publicly recognizable as law and generally to share in those norms of treatment. Since part of what it is to be an exemplar of that type of artifact is that it bears some of those norms, to the extent the creation is successful (determined in law by the criteria of legal validity) the token carries some of those general norms of treatment and possibly creates new ones in terms of what is distinctive about that exemplar. That it is a type of institution means that it confers a special status on some members or other elements within its ambit. That special status tends to include deontic powers to give non-prudential reasons by the institution's own lights. Where those reasons are legitimately authoritative, the institution has successfully created the non-prudential reasons it claims to have created. Where they are not legitimately authoritative, they merely alter empirical facts about how members of the institution are likely to treat actions in compliance and non-compliance with those contextual norms (implying a possible triggering of prudential reasons to comply). This picture therefore holds out the possibility of the law creating entirely new reasons for action and explains the contours of that normativity. 